\title{
PerCursos
}

\section{O corpo-sujeito, interconexões entre paisagem, assemblage e a rua - um exercício metodológico propositivo}

\section{Resumo}

A concepção de Merleau-Ponty (2006) sobre corpo-sujeito/fenomenal indica a existência ativa do corpo perante o mundo. Este texto aborda a relação corpo-sujeito com a paisagem constituída pela posição do corpo-espaço (horizonte de pensamento). A produção de uma metodologia que mobilize o corpo na compreensão das percepções espaciais na vivência cotidiana da rua, por meio do trabalho de campo, é outro aspecto propedêutico do presente ensaio. Disso posto, foram produzidos três exercícios teóricopráticos a partir da posição do corpo-pesquisador-espaço. Esses exercícios são apresentados no texto na forma de narrativas e contemplam o corpo atravessado pela consciência de realidade, imaginário e espaço - mediados pelo 'pensamento-paisagem'. A articulação dessas reflexões com as discussões sobre assemblage remete a uma perspectiva de abordar fenômenos fluidos e efêmeros na Geografia.

Palavras-chave: Corpo. Espaço. Paisagem. Posição. Fenomenologia.
Bruna da Silva Sassi

Mestre em Gestão do Território pela Universidade Estadual de

Ponta Grossa - UEPG. Brasil

bruna-sassi@hotmail.com

\section{Almir Nabozny}

Doutor em Geografia pela Universidade Federal do Rio Grande Sul - UFRGS. Docente permanente no Programa de Pós-

Graduação em Geografia da Universidade Estadual de Ponta Grossa - UEPG.

Brasil

almirnabozny@yahoo.com

\section{Bruna lara Lorian Chagas}

Mestre em Gestão do Território pela Universidade Estadual de

Ponta Grossa - UEPG.

Doutoranda no Programa de Pósgraduação em Geografia na Universidade Estadual de Ponta Grossa - UEPG. Brasil

brunaiarachagas@gmail.com

\section{Para citar este artigo:}

SASSI, Bruna da Silva; NABOZNY, Almir; CHAGAS, Bruna lara Lorian. O corpo-sujeito, interconexões entre paisagem, assemblage e a rua - um exercício metodológico propositivo. PerCursos, Florianópolis, v. 22, n.48, p. 456 - 483, jan./abr. 2021.

DOI: $10.5965 / 1984724622482021456$

http://dx.doi.org/10.5965/1984724622482021456 


\title{
The subject body, interconnections between landscape, assemblage and the street - a methodological exercise
}

\begin{abstract}
Merleau-Ponty's (2006) conception of bodysubject/phenomenal indicates the active existence of the body before the world. This text addresses the relation body-subject with the landscape constituted by the position of the body-space (horizon of thought). The production of a methodology that mobilizes the body in the comprehension of spatial perceptions in the daily experience of the street, through field work, is another propedeutic aspect of this essay. Hence, three theoretical and practical exercises were produced from the position of the body-researcher-space. These exercises are presented in the text in the form of narratives and contemplate the body crossed by the consciousness of reality, imaginary, and space mediated by the 'thought-landscape'. The articulation of these reflections with discussions about assemblage refers to a perspective of approaching fluid and ephemeral phenomena in Geography.
\end{abstract}

Keywords: Body. Space. Landscape. Position.

Phenomenology. 


\section{Introdução}

Este ensaio ${ }^{1}$ aborda a noção de corpo-sujeito (MERLEAU-PONTY, 2006) na ciência geográfica e a paisagem como um horizonte de mediação entre os corpos, isto é, a paisagem assumindo forma de pensamento geográfico por meio de um corpo-paisagem. Também é discutida a forma de pensamento do trabalho de campo, em que a posição 'corpo-pesquisador', em diferentes situacionalidades, compõe um fazer geográfico fenomenológico.

O texto é construído com exercícios narrativos, propondo a articulação destes com as discussões sobre assemblage, remetendo a uma perspectiva de abordar fenômenos fluidos e efêmeros na Geografia no plano de um pensamento que se produz relacionalmente (sujeitos-sujeitos) e que também evoca o contingente e o transformativo.

As assemblage, neste caso, podem ser compreendidas, conforme o exposto por Colin McFarlane (2009), enquanto organizações socioespaciais provisórias, formações heterogêneas e fluidas que enfatizam os processos, os movimentos, a multiplicidade. Essa plasticidade compõe o pensar deste trabalho, que, de forma propositiva, se relaciona com uma discussão ampliada do ethos na ciência moderna, nos termos em que aquilo que é narrado a partir dos exercícios de campo (estar na rua com os outros) nem sempre será vislumbrado em outros possíveis arranjos, a exemplo de uma pesquisa futura, rompendo com a força do argumento positivista da ciência como prática de verificabilidade baseada na repetição.

A complexidade da realidade jamais será abarcada pela ciência, pois a produção científica é viabilizada por meio de olhares sobre recortes específicos, ou seja, a construção processual da objetividade científica. Consequentemente, a estruturação da ciência objetivista em busca da verdade científica balizou as discussões das lógicas

\footnotetext{
1 De acordo com Almeida (2013), a forma do ensaio não esgota o sujeito e o convida a outros modos de percurso teórico, mais flexíveis no tocante à validade científica concebida pelo polo racionalista da modernidade (GOMES, 1996). Conforme Marandola Jr. (2016), a fenomenologia é uma busca por diferentes caminhos; nesse sentido, o arranjo teórico-metodológico deste ensaio é forjado por meio de leituras sistemáticas e por trabalhos de campo realizados em 2018, constituindo um movimento científico de possibilidades metodológicas.
} 
científicas, em termos epistemológicos, nas reflexões de filósofos como Karl Popper (1902-1994) e Paul Feyerabend² (1924-1994), os quais ilustram essa problemática.

Dessa maneira, a abertura científica aos conteúdos do mundo vivido apregoados pela fenomenologia foi proporcionada, de acordo com Emanuel Davim e Eduardo Marandola Jr. (2016), pelo impacto epistêmico da obra Contra o método (FEYERABEND, 1977). Para Feyerabend (1977), o mundo vivido é constituído, por exemplo, de questões ilógicas e, por isso, potencializa novos saberes, bem como o surgimento de outros expedientes de apreensão científica. O pensamento de filósofos como Martin Heidegger (1889-1976) e Edmund Husserl (1859-1938), posto que formularam críticas ao Positivismo e à ciência convencional, é indicador dos novos diálogos que a ciência vai empreender com a Filosofia no campo dos significados (DAVIM; MARANDOLA JR., 2016).

Isso posto, os conteúdos do mundo vivido para além do tangível passaram a ser considerados em estudos que contemplam a densidade de nossas relações espaçotemporais. Maria Geralda Almeida (2013), ao citar o texto de Joan Nogué e Joan Romero (2006), que trata sobre o invisível e o intangível, menciona que o intangível não é sinônimo de invisível, mas sim uma característica fenomênica de difícil apreensão. Nogué e Romero (2006), por sua vez, destacam que o invisível, o intangível e o efêmero (tempo) se configuram em processos espaciais marginalizados no discurso geográfico moderno.

Dessa forma, considerando que existem posições para pensar as coisas no mundo, trabalha-se nesta pesquisa com concepções mais abrangentes de realidade e, consequentemente, de ciência. Para Maurice Merleau-Ponty (2006), a fenomenologia é o estudo das essências como uma mediação, pois, para esse autor, a consciência não é transcendental, mas é perceptiva, uma vez que está atrelada à experiência. Assim, a visão fenomenológica de ciência é mais adequada a essa reflexão por trabalhar na escala da experiência (MARANDOLA JR., 2016).

Nessa perspectiva, sabe-se que o que experienciamos no mundo se revela em nossa subjetividade. É nesse sentido que, expandindo a noção de corpo, o filósofo

\footnotetext{
${ }^{2}$ Ainda que a perspectiva de Feyerabend se distancie da concepção fenomenológica ao longo do texto para a exposição do corpo e da corporeidade, utilizaremos o pensamento do autor como endosso da metodologia da 'situacionalidade' utilizada por nós, especificamente na narrativa de número três.
} 
francês inclui a visão subjetiva de que habitamos um mundo próprio e, por isso, temos uma experiência de mundo antes de uma reflexão sobre ele. Por esse ângulo, aquilo que nos circunda não se constitui apenas de objetos, mas de significantes para um significado, não estando deslocados e distantes de nós. Contudo, nossa experiência se dá de forma concreta por meio de um corpo que nos possibilita o existir; ainda que ao iniciar suas reflexões sobre o ser humano Merleau-Ponty (2006) tenha sido materialista, suas considerações começam a se diferenciar quando ele estrutura a noção de corpo-sujeito, em que o corpo não consiste em um objeto estudado nem somente em um organismo biológico com suas características físico-químicas, nem somente em um corpo em relação com outros corpos e objetos, mas em um agente ativo de sua própria existência no mundo.

Dessa maneira, as dicotomias sujeito/objeto, pesquisador/pesquisado são negadas em termos de logos científico, pois se assemelham ao tempo e ao espaço na perspectiva (re)imaginativa (MASSEY, 2008), na qual eles não podem estar separados. O fazer fenomenológico está imbuído de imbricações que também impossibilitam cindir o corpo e o espaço, o corpo e o tempo, o corpo e o pesquisador. Desse modo, nos questionamos, a partir de nosso olhar e fazer fenomenológico, se é possível construir metodologias de apreensão da urbe contemporânea a partir de nossas experiências-encarnadas.

Sobre o fazer fenomenológico que se volta para a experiência geográfica do serno-mundo, parte-se da noção de que fazer fenomenologia é produzir questões através de nossa própria atuação (MARANDOLA JR., 2013). Em consequência, no presente texto, há uma variação linguística proposital: quando necessário, os verbos são conjugados em primeira e terceira pessoas. Quando nos referirmos ao trabalho no mundo por meio de uma experiência que demanda intencionalidade, utilizaremos a primeira pessoa, e, para salientar perspectivas de outros autores, busca-se a impessoalidade com o uso da terceira pessoa.

Assim, de acordo com Marandola Jr. (2016), há tantas geografias quantos geógrafos partilhando uma busca, contudo não o mesmo caminho. O olhar para as invisibilidades do cotidiano urbano abre portas para reconhecer os indivíduos não como 'sociedade' a partir das concepções estruturalistas, mas como sujeitos. 
É refletindo sobre a apreensão do urbano pela dinâmica das/nas ruas que o recorte espacial escolhido para essa reflexão como estudo de caso foi a Rua Fernandes Pinheiro, localizada na cidade de Ponta Grossa, Paraná. A escolha se fez por seu potencial comercial atrelado não só à vivência experimentada na rua mas à questão da sobrevivência por intermédio dessa vivência. Alocada ao redor de grandes lojas, mercado, farmácias, lanchonetes e bares, configura-se em um local com grande quantidade de passantes, sejam errantes (JACQUES, 2012), sejam trabalhadores (formais e informais), sejam, ainda, moradores das 'regiões' próximas que acabam compondo relações sociais nessas esferas.

Nesse espaço, encontramos passantes, moradores de rua, profissionais ambulantes de diversas categorias, ciganos, prostitutas etc.; indivíduos que sobrevivem nas cidades por meio de profissões irregulares segundo a lógica do mercado de trabalho formal. Essa experiência através do trabalho é determinante para nossa compreensão do cotidiano através da rua, entretanto buscamos uma compreensão que se aproxima do texto de Richard Sennett (1997), no qual o autor argumenta que a história das cidades pode ser contada através de suas ruas e corpos. A rua escolhida também desperta uma sensação de deslocamento espaço-temporal e configura, por meio da corporalidade, um horizonte-paisagem que coexiste nesta pesquisa.

Destarte, a temática corporal dialoga com uma demarcação do conhecimento científico que questiona a dualidade proposta por René Descartes (1596-1650) no 'cogito ergo sum'. Essa concepção não dicotômica contribui para a existência de um ser-nomundo conforme a fenomenologia merleau-pontyana, visto como agente ativo do movimento e da intencionalidade, permeado por sensações que culminam numa percepção subjetiva da realidade. Dessa maneira, a importância necessária à temática corporal, em termos de uma pesquisa encarnada como mote de contribuição a perspectivas interdisciplinares, será retratada a seguir. 


\section{O corpo como fenômeno geográfico/espacial}

Em reflexões que problematizam vivências espaciais³, o corpo pode ser entendido como uma escala quando partimos em busca de compreensões do particular para o universal, do individual para o coletivo. Os autores Costa, Goergen e Durgante (2017) destacam que o corpo é uma das quatro perspectivas ligadas à escala, sendo estas: a) forma sincrônica do espaço; b) forma diacrônica; c) definição de estruturas espaciais; d) desconstrução das estruturas e valorização do vivido. Esta última implica "em uma relação teórica escalar diretamente ligada ao corpo humano, cujos espaços e espacializações ora emanam deste corpo, ora conduzem à formação deste corpo" (COSTA; GOERGEN; DURGANTE, 2017, p. 354).

Sendo também um fato histórico e cultural, o corpo é mencionado por Sennett (1997) em seu livro Carne e a pedra: o corpo e a cidade na civilização ocidental, em que o autor faz uma retrospectiva sócio-histórica da visão corporal desde Atenas até as grandes cidades, como Paris e Londres, abordando o corpo relacionado às imposições espaciais através da Arquitetura. Logo, um fato histórico se faz a partir de experiências, e a experiência é a escala de manifestação dos fenômenos de acordo com Marandola Jr. (2016). Para nós, o corpo é o lócus de nossa experiência metodológica no espaço/paisagem da Rua Fernandes Pinheiro, pois, de acordo com Sennett (1997, p. 17): “as relações entre os corpos humanos no espaço é que determinam suas relações mútuas, como veem e se ouvem, como se tocam ou se distanciam”.

Não à toa, o corpo como um instrumento de análise foi pensado ao longo da história enquanto idealização, a exemplo da Grécia antiga (BARBOSA; MATOS; COSTA, 2011), sendo problematizado em vários campos do conhecimento, como na Arquitetura, em termos de movimentação/sensação espacial dos corpos para o planejamento urbano (SENNETT, 1997). Da mesma forma, o corpo foi pensado como uma janela para compreender a construção social da cidade, do urbano e dos lugares através dos sujeitos e de suas emoções, como faz a geógrafa Alicia Lindón (2009). Isso posto, o corpo tem a capacidade de afetar, mas também tem imposições políticas, religiosas, biológicas,

\footnotetext{
3 Para aprofundamento sobre vivências espaciais, consultar o livro de Otto Bollnow (2008): BOLLNOW, Otto Friedrich. O homem e o espaço. Curitiba: UFPR, 2008. 327 p.
} 
legislativas etc. que retratam a construção social de uma época, vide a ideia de corpomercadoria (JACQUES, 2012). Jacques (2012) destaca um corpo distante dos processos de espetacularização, o corpo dotado de sensibilidade, o corpo errante ${ }^{4}$.

Na ciência geográfica, o corpo ganhou visibilidade por meio dos estudos sobre gênero e sexualidade. Nos estudos de gênero, o corpo geralmente é concebido como espaço de identidades/territorialidades ou é pensado no espaço como categoria geográfica para a leitura do espaço urbano. Em Elias Lopes de Lima (2007), o corpo aparece como perspectiva geográfica através da experiência perceptiva do espaço como paisagem. Embora não seja um fenomenólogo, o geógrafo Yi-Fu Tuan (2013), influenciado pela psicologia genética, considerou o corpo em seus estudos sobre percepção biológica do meio e aportes para a experiência do homem no mundo. Tuan (2013) parte da ideia da experiência que está voltada ao mundo exterior para entender de que forma o indivíduo conhece e constrói a realidade, primeiramente através dos sentidos, em seguida por meio do pensamento e das emoções que dão colorido a essa experiência humana. Para esse autor, os princípios fundamentais da organização espacial são a postura e a estrutura do corpo e as relações entre as pessoas.

$\mathrm{Na}$ contemporaneidade, diante da abertura instaurada pela fenomenologia, a temática corporal, ainda que perifericamente, ganha visibilidade na ciência quando se considera o espaço geográfico.

Quando se trata do espaço, Tonino Bettanini (1982) aponta que este é dotado de invisibilidades, e as percepções espaciais na abordagem do cotidiano podem ser pensadas a partir do corpo, visto que é o corpo que enraíza a existência. Essas invisibilidades são vistas por Nogué e Romero (2006) como componentes do espaço geográfico, e os autores, em vista disso, aludem: "hay que mirar lo que no se ve". Igualmente, Lima (2014b, p. 9) menciona que "o espaço geográfico está prenhe de conteúdos informes a serem descobertos ou apresentados". Da mesma forma, Eric Dardel afirma:

\footnotetext{
4 Nas palavras de Jacques (2006), o errante é aquele que busca o estado de espírito (ou melhor, de corpo) errante, que experimenta a cidade através das práticas e ações subjetivas, que percebe o espaço urbano para além da representação meramente visual.
} 
Conhecer o desconhecido, atingir o inacessível, a inquietude geográfica precede e sustenta a ciência objetiva. Amor ao solo natal ou busca por novos ambientes, uma relação concreta liga o Homem à Terra, uma 'geograficidade' (géographicité) do Homem como modo de sua existência e de seu destino. (DARDEL, 2011, p. 1)

A geograficidade é considerada por Lima (2015) enquanto modo geográfico característico das relações sociais e, portanto, como alternativa metodológica a partir das relações de corporeidade; nesse ponto de vista, o autor compreende o corpo como expediente metodológico para acessar conteúdos reificados e a corporeidade como forma alternativa de compreensão da reprodução do espaço geográfico e de revalorização dos sujeitos protagonistas.

\subsection{Corpo-sujeito}

A fenomenologia de Merleau-Ponty espacializa o corpo ao vê-lo como um corpopróprio ou corpo-sujeito (MERLEAU-PONTY, 2006) ou, ainda, corpo fenomenal, como estrutura física e vivida ao mesmo tempo, uma vez que a percepção dos sentidos se dá através da corporeidade. A compreensão de corpo desse autor vem do fato de que ambos, corpo e gestos/expressão, são vinculados à percepção, pois é através dela que fazemos nosso primeiro contato com o mundo. Logo, a percepção é imediata e direta e relaciona-se com um aparato sensório-motor. Assim, nos expressamos e conhecemos o mundo através de nosso corpo, o qual se configura como um mediador das relações sociais com os outros, com o mundo e com nós mesmos através da percepção.

A percepção está ligada à atitude corporal na medida em que o corpo se dirige às coisas do mundo através de uma intencionalidade e, consequentemente, constrói seu esquema corporal. Não se trata de uma construção, não é causada por objetos sobre nós, nem sobre nosso corpo e as coisas. É a relação entre elas e nós, nós e elas, uma relação possível porque tanto as coisas como nós somos corporais. A diferença é que as coisas (reificação) não têm a capacidade de perceber o mundo e a si mesmas (MERLEAUPONTY, 2006). Desse modo, há uma relação com o mundo através da sensibilidade antes de algo transformar-se em pensamento. No entanto, não existe padronização da 
percepção, porque cada indivíduo é um ser diferente a cada percepção, fazendo conexões singulares entre os sentidos e a sua subjetividade.

Em vista disso, o corpo-próprio (MERLEAU-PONTY, 2006) é o corpo-sujeito, sendo visto como fenomenal por ser agente ativo de sua existência, potência motora e afetiva na medida em que se dirige às coisas do mundo e volta-se ao ambiente que ele mesmo constrói. Sendo assim, nas palavras do filósofo em questão:

Eu não sou o resultado ou o entrecruzamento de múltiplas causalidades que determinam meu corpo ou meu "psiquismo", eu não posso pensarme como uma parte do mundo, como o simples objeto da biologia, da psicologia e da sociologia, nem fechar sobre mim o universo da ciência. Tudo aquilo que sei do mundo, mesmo por ciência, eu o sei a partir de uma visão minha ou de uma experiência do mundo sem a qual os símbolos da ciência não poderiam dizer nada. (MERLEAU-PONTY, 2006, p. 3)

Para o filósofo, nossa experiência de ser-no-mundo é sempre corporificada; somos uma consciência encarnada em um corpo. Destarte, refletindo sobre a significância do que é espaço, Merleau-Ponty (2006, p. 328) aponta: “O espaço não é o ambiente (real ou lógico) em que as coisas se dispõem, mas o meio pelo qual a posição das coisas se torna possível". Por isso, em nossa experiência perceptiva de mundo, o corpo é dotado de uma espacialidade que ao mesmo tempo é capaz de fazer e fazer-se e, assim, produz uma corporeidade singular nas suas relações.

Essa perspectiva relaciona-se com a geograficidade, uma vez que o corpo transcende a si mesmo pelas suas qualidades proprioceptivas e diacríticas (LIMA, 2015). Nessa abordagem, o corpo, bem como o espaço, é paradoxal, pois, na medida em que sofre imposições hegemônicas, tem a capacidade de subvertê-las (LIMA, 2015). Contudo, se o espaço é reflexo e condição (concepção estrutural) e o corpo é seu agente mediador como potência de reversibilidade paradoxal, o corpo e o espaço não podem ser entendidos como sistemas fechados (concepção pós-estruturalista), assim defende Doreen Massey: 
O espaço jamais poderá ser uma simultaneidade completa, na qual todas as interconexões já tenham sido estabelecidas e no qual todos os lugares já estão ligados a todos os outros. Um espaço, então, que não é nem um recipiente para identidades sempre já constituídas em um holismo completamente fechado. É um espaço de resultados imprevisíveis e de ligações ausentes. Para que o futuro seja aberto, o espaço também deve sê-lo. (MASSEY, 2008, p. 32)

Segundo Lima (2014b), em uma análise nomotética, em que há a decomposição de elementos e relações seguindo uma análise objetivista, não é possível o reconhecimento dos sujeitos como reais agentes transformadores do espaço, devido a uma visão fechada sobre a realidade e que trabalha com uma única narrativa perante aspectos e fenômenos gerais. Já a concepção de espaço geográfico elucubrada por Massey (2008) e utilizada por nós elucida a fluidez do espaço e das suas relações corpóreas. Nesse sentido, vislumbramos associações entre o corpo-sujeito e as relações de que trataremos a seguir.

\subsubsection{A relação corpo-sujeito com a paisagem constituída pela posição do corpo}

Considerando a pergunta "o que a fenomenologia ainda pode fazer pela Geografia?", do texto "Geografias do porvir" de Marandola Jr. (2016), dedicamo-nos a refletir sobre ela nesta parte do texto.

A relação do corpo com o espaço pode ser compreendida pela perspectiva de paisagem desenvolvida no ensaio filosófico literário Poética e Filosofia da Paisagem, de Michel Collot (2013), ou seja, como um procedimento estratégico para novas formas de perceber o mundo. A partir daí, se destaca a noção da posição do corpo em relação ao mundo, em que a percepção do sujeito é que torna o ambiente uma paisagem; além disso, a experiência se apresenta como um horizonte de pensamento paisagístico de quem escreve sobre o mundo a partir de uma visão corporificada.

Para Jean-Marc Besse (2006), a paisagem - seja enquanto categoria do pensamento, estilo literário, seja enquanto uma 'objetivação empírica' — tem sua aparição na arte, na ciência e na literatura em termos de rompimento com a ideia do 'universal', que é cara à modernidade. De forma paradoxal, a paisagem expressa concomitantemente o infinito dado pelo processo dialético de olhar as minúcias da 
observação e faz suscitar questões para além de uma organização dada, em virtude de que "a Geografia está do lado da percepção, a paisagem do lado do sentir” (BESSE, 2006, p. 79).

Portanto, conforme nosso trabalho de campo é esmiuçado nas narrativas que se seguirão, há na Rua Fernandes Pinheiro uma “dança intrínseca5” (BENETT, 2005, p. 454, tradução nossa) entre os significantes e suas "urgências, tendências e pressões de outros corpos", sendo inter-relações constituintes das paisagens em assemblage (BENETT, 2005, p. 454) que causam uma impressão percebida a partir do experimentado, remetendo às reflexões de Dardel (2011, p. 30), nas quais "a paisagem é um conjunto, uma convergência, um movimento vivido, uma ligação interna, uma 'impressão'. Que une todos os elementos". Válido ater-se à longa citação:

Um relevo não é para Dardel uma simples representação produzida pelo sujeito; é uma forma, e se na sua potência, esta forma vem animar a vida mental daquele que a visualiza, ela o faz à maneira de um acontecimento ou de um movimento transpassante. Esta realidade geográfica é um evento [...] mais do que um 'objeto' colocado diante de um 'sujeito'. É um dado elementar da vida do espírito humano em contato com a Terra. É uma qualidade essencial do lugar em que o homem se encontra, dando à sua experiência do momento uma essência e uma densidade próprias. Este relevo, esta luz, mas também esta construção ou este aglomerado urbano, impõem à minha percepção a sua potência e estruturam de modo radical ou elementar não apenas minha experiência, mas também meu pensamento sobre $o$ mundo a partir deste lugar. $O$ espaço geográfico, do qual não se pode na verdade falar no singular (porque a geografia se depara essencialmente com espaços diferenciados), é a reunião destes dados elementares que revelam aos que os frequentam a presença de significados flutuantes na superfície do mundo e que às vezes se deixam captar. A 'consciência geográfica' (segundo expressão de Dardel) se distribui, então, segundo polaridades, qualidades intensidades, que constituem espacialidades elementares com as quais finalmente o geógrafo de ofício deverá se defrontar. (BESSE, 2006. p. 88)

E a paisagem?

5 Traduzido de “intricate dance" (BENETT, 2005, p. 454). 
Entenda-se bem, a paisagem se deixa ver, mas, além do simples pitoresco, na ordem própria da visibilidade que a paisagem oferece, o ser humano, ao situar-se nela descobre as dimensões do seu ser. A paisagem é ambiente, mas círculo fechado: ela é desdobramento, ela é fundamentalmente um horizonte que se abre. Na verdade, ela só é geográfica, diz Dardel, 'pelos seus prolongamentos, pelo plano de fundo real ou imaginário que o espaço abre além do olhar'. (BESSE, 2006. p. 92, grifos do autor)

Em acordo com as palavras de Besse (2006), a seguir abordaremos a metodologia experienciada neste trabalho. Nossa experiência de pesquisa incorpora e desdobra-se nas narrativas propostas em um horizonte-paisagem por meio do corpo-sujeito (MERLEAUPONTY, 2006) por conter como exercício metodológico na Rua Fernandes Pinheiro o que também chamamos de atravessamentos: atravessar e ser atravessado pela urbe contemporânea.

\section{Metodologia}

O caráter investigativo da pesquisa em tela confabula com Merleau-Ponty (2006) quando este autor menciona que a ciência é uma explicação do mundo percebido, assim jamais pode ter o mesmo sentido de ser-no-mundo. Desse modo, quando trabalhamos com percepções, tanto da pesquisadora ${ }^{6}$ quanto dos outros participantes, existe uma subjetividade implícita agindo como filtro perceptivo de diálogos e ações, compondo um fazer fenomenológico. Dessa forma, como metodologia, realizamos uma projeção do olhar sobre a Rua Fernandes Pinheiro em Ponta Grossa, Paraná, a partir de uma visão aproximada ao corpo, buscando compreender as percepções espaciais dos sujeitos que vivenciam o cotidiano da rua em questão.

A projeção do olhar faz com que a paisagem, enquanto ambiente percebido a partir dos significantes7, seja compreendida nesta discussão como uma organização

\footnotetext{
6 'Pesquisadora' refere-se à primeira autora do texto e suas errâncias metodológicas na Rua Fernandes Pinheiro.

7 Reconhecemos que a maior parte das reflexões relacionadas ao conceito de assemblage trabalha os aqui chamados 'significantes' enquanto elementos humanos e não humanos. Optamos pelo uso de significantes por considerá-los como elementos que se articulam à percepção da paisagem.
} 
socioespacial provisória, uma paisagem em assemblage. Anderson e McFarlane (2011) explicam que o conceito de assemblage vem sendo utilizado como fio condutor explicativo para fenômenos das áreas da Geografia, Antropologia, História, Artes, Ecologia e da Arquitetura, por exemplo. Para os autores, na Geografia esse é um conceito utilizado de maneiras muito diversas e apresenta certa proximidade com outros bastante utilizados nesse campo do conhecimento, como rede, território, espaço e meio, podendo contribuir fortemente para as reflexões relacionadas às dinâmicas socioespaciais (ANDERSON; MCFARLANE, 2011).

No decorrer deste trabalho, utilizamos o conceito de assemblage em uma abordagem geográfica, buscando compreender a partir de exercícios de projeção do olhar as paisagens e imaginários relacionados a processos de inter-relações — de sujeitos e sujeitos, sujeitos e objetos, sujeitos e o mundo - que acontecem na Rua Fernandes Pinheiro e que se relacionam a essa rua. Essas inter-relações foram observadas sob a premissa indicada por Juan Carlos Skewes (2016), ou seja, de que acontecem sem autonomias e soberanias entre os significantes humanos e não humanos, materiais e imateriais, mas como assemblage que extrapola o sentido conceitual atribuído à palavra, sendo uma assemblage no sentido artístico, uma bricolagem que ganha sentido a partir da experiência.

Uma paisagem em assemblage é uma assemblage vivida, conforme indica Jane Benett (2005), que acontece pela vivência, pelo movimento e pela interação com os significantes. As assemblage, enquanto provisórias, enfatizam a heterogeneidade e a contingência de práticas e interações significantes a partir do reconhecimento do “caráter essencialmente corporificado da ação humana e do campo intersubjetivo de todos os atos humanos" (BENETT, 2005, p. 452, tradução nossa) ${ }^{8}$. Neste ensaio, pela própria existência e projeção do olhar em relação à Rua Fernandes Pinheiro, consideramos como 'significantes' os indivíduos, os animais, a arquitetura composta de novas e antigas construções. Na contemporaneidade, estas figuram em sua maioria como empreendimentos de uma ampla variedade funcional, isto é, açougue, agropecuária,

\footnotetext{
8 Tradução de: "the essentially embodied character of human action and the intersubjective field of all human acts"” (BENETT, 2005, p. 452).
} 
brechós, briques (loja de venda de móveis e eletrodomésticos usados), cafeterias, empresa de fotografia, empresa de motoboys/mototáxis, hotel, imobiliária, lanchonetes, loja de artigos religiosos e esotéricos, loja de instrumentos musicais, loja de departamentos, mercado, ótica, restaurantes, salões de beleza.

Em vista disso, no presente trabalho propomos refletir sobre a busca de uma metodologia possível em fenomenologia - diferentemente de algumas referências sobre o corpo, como em Marilena Chauí (2009), Costa, Goergen e Durgante (2017), em que é possível perceber a ausência da experiência encarnada do fenomenólogo. Tal metodologia refere-se à situacionalidade e ao movimento do corpo do pesquisador, bem como à sua abertura ao horizonte-paisagem, enquanto proposta de mediação compreensiva dos corpos na Rua Fernandes Pinheiro, viabilizadas por trabalhos de campo erráticos $^{9}$ e situacionistas ${ }^{10}$. Isso posto, trata-se de um híbrido metodológico ancorado na mediação do corpo-sujeito (MERLEAU-PONTY, 2006) e a paisagem em assemblage (teoria).

A fim de compreender as percepções espaciais de sujeitos que compõem o cotidiano urbano atrelado à rua escolhida, lançamos mão de campos exploratórios. Uma primeira interpretação detectou indivíduos e seus perfis de trabalho informal (categoria da percepção dos pesquisadores). Existem desde vendedores de artesanato, hippies ${ }^{11} \mathrm{e}$ idosos, vendedores que oferecem diversos tipos de produtos, como: brinquedos, utensílios domésticos, CDs, DVDs, tênis, roupas, óculos, meias, cintos, frutas, verduras, pães, cigarros e outros produtos fáceis de carregar para esse tipo de empreitada, em que o escritório é a calçada. Alguns trabalhadores são ponta-grossenses, contudo, a maioria é de migrantes oriundos de outras regiões do país e de imigrantes, como peruanos, haitianos, entre outras etnias. Outro grupo a ser pensado são as prostitutas que

\footnotetext{
9 De acordo com Jacques (2012), são práticas de errância urbana em que perder-se pela cidade faz parte do trajeto, como fizeram Baudelaire (1821-1867), Edgar Allan Poe (1809-1849) e tantos outros que foram movidos, segundo Walter Benjamim (1892-1940), pela arte ou educação de se perder pela cidade.

${ }^{10}$ A metodologia situacionista como recurso geográfico advém da preocupação dos situacionistas com o espaço articulado pelas relações de troca na cidade. De acordo com Carla Hermann (2005), as práticas situacionistas podem ser utilizadas como recurso metodológico geográfico no campo do espaço urbano. Assim, a prática espacial da deriva pode ser utilizada no sentido de deixar-se levar pela cidade, criar situações, utilizar-se da psicogeografia em trajetórias urbanas.

${ }^{11}$ Indivíduos que não seguem valores tradicionais de consumo e que pregam a paz e o amor, tendo como sobrevivência a venda de seus próprios artesanatos.
} 
percorrem as ruelas (adjacências à Rua Fernandes Pinheiro), entre bares, em grupo ou sozinhas; indivíduos que se fazem por meio do que se percebeu como um corpo sensual.

Essa relação tão singular do expressar-se na/através da rua como forma de trabalho chama-nos a atenção quanto à disposição dos sujeitos que têm na rua a sua forma de trabalho, articulando-se em redes (econômica, social e simbólica) e criando laços de solidariedade. De acordo com nossas primeiras observações, aliadas ao embasamento teórico consultado, podemos dizer que, em sua maioria, esses sujeitos são produtores de locais efêmeros e provisórios e concebem o espaço como parte de sua subjetividade, exercendo nele sua corporeidade.

Isso posto, a (re)imaginação da rua de quem escreve este texto ocasiona um redimensionamento que mistura composições do passado e do presente, no momento em que se cria o futuro. Há uma sensação de que as vivências experimentadas naquele local sejam também vivenciadas de forma semelhante por outros corpos. Logo, o corpo é fundamental para essa compreensão dos sujeitos através de suas vivências corporais, pois os sujeitos são considerados em seu desdobramento espacial e suas interações. Nesse sentido, as figuras que compõem a maioria dos indivíduos que circulam pela rua escolhida são os vendedores ambulantes.

Mas como esses corpos se tornam ambulantes para nós? Considerando que a rua pode ter generalizações - no entanto o corpo é sempre único- e que a dinâmica do cotidiano urbano se faz em inter-relações multiescalares, em que há relação entre o particular e o universal, partimos de um trabalho de campo com a perspectiva corporal. Compreendemos esses indivíduos como corpos em atuação ativa no espaço público, a rua. Logo, as inter-relações elencadas são vistas como relações corporais com eles mesmos e com os outros e são imbricadas com a geograficidade, com a intencionalidade de cada corpo diante do mundo. De acordo com Lima:

A história nos revela que o indivíduo em si mesmo não corrobora transformações significativas no corpo social e, portanto, no espaço, senão como indivíduo concreto, isto é, enredado nos aspectos globais de sua realidade social. (LIMA, 2014a, p. 21) 
Quando Lima (2015) nos fala do indivíduo concreto, há uma relação da corporeidade como consequência histórico-material. Acrescentando a experiência encarnada de quem escreve sobre a rua, temos a reflexão sobre o pensamento-paisagem (COLLOT, 2013) atuando como horizonte do deslocamento e do olhar perante a rua. Por conseguinte, apreender o espaço por diferentes posições está ligado à posição corpórea e à paisagem que nos atravessa. A paisagem, para Collot (2013), é um fenômeno produzido pelo encontro entre o mundo e um ponto de vista. Trabalhando na perspectiva de pontos de vista aliados a posições corpóreas, estabeleceremos a seguir exercícios que cruzam o pensamento-paisagem e a posição do corpo sendo espaço.

\subsection{Narrativas corpo-sujeito-paisagem como potencialidade metodológica}

Os exercícios experienciais apresentados fazem parte de um constructo empíricoteórico e são apresentados na forma de três narrativas na Figura $1^{12}$.

Figura 1 - Síntese dos exercícios experimentais - narrativas 1, 2, 3

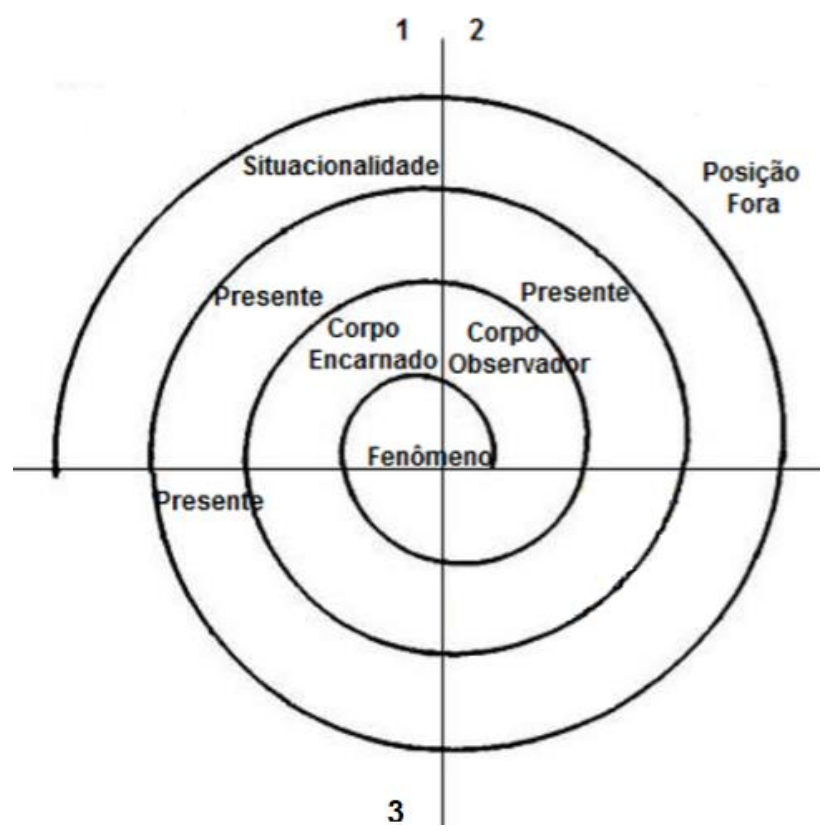

Fonte: Autores (2018)

\footnotetext{
${ }^{12}$ A Figura 1 destaca a relação espacial-temporal tramada entre a pesquisadora e a rua considerando a posição do corpo-pesquisadora; é uma síntese metodológica da prática em torno do fenômeno.
} 
Essa construção é composta por uma situacionalidade que se faz ao vivenciar o espaço público ponta-grossense, principalmente na Rua Fernandes Pinheiro. Considerando a potencialidade do espaço geográfico, as teorias utilizadas e a produção científica teórica sem aproximações práticas sobre esses temas, os exercícios como potencialidades metodológicas fazem parte de uma experimentação metodológica prática, que visa relacionar as concepções de corpo-sujeito de Merleau-Ponty (2006) com o olhar paisagístico pela posição do corpo sendo espaço.

Quando Marandola Jr. (2013) nos fala sobre a experiência do ser-no-mundo pelo fazer geográfico, consideramos enraizada nessa concepção a experiência corpórea. Por conseguinte, quando minha (nossa) intencionalidade coloca-me diante do mundo em minha potência geográfica, estou imbuída de minha geograficidade, pois, de acordo com Dardel:

A situação de um Homem supõe um espaço onde ele se move; um conjunto de relações e de trocas; direções e distâncias que fixam de algum modo o lugar de sua existência. Perder a localização, é se ver desprovido de seu lugar, rebaixado de sua posição eminente, de suas relações, se encontrar, sem direções, reduzido à impotência e à imobilidade. (DARDEL, 2011, p. 19)

Entretanto, conforme meu corpo está disposto no espaço e meu pensamentopaisagem está carregado, minhas percepções e, logo, minhas visões de mundo são alteradas. O corpo é dotado de potencialidades ainda não exploradas e constitui um lócus de possibilidades interpretativas sobre a realidade, o imaginário, o intangível e o tangível.

\section{Narrativas de um "ethos" efêmero na urbe contemporânea}

Configurando um "ethos efêmero" que também compõe o cotidiano geográfico de ruas populares, os fenômenos encarnados descritos nas narrativas que se seguem foram elaborados a partir de situações, desvios e atravessamentos de corpos-sujeitos 
(pesquisadora e participantes) que reverberam em possibilidades de adentrar as camadas que compõem a urbe contemporânea.

\title{
4.1 Narrativa 1 - quando o corpo é levado pela situacionalidade
}

As sensações experimentadas por esse corpo na rua acontecem como se o corpo e a rua estivessem intimamente ligados. Como se o cimento das paredes, o calçamento antigo de paralelepípedos, o olhar sobre as construções compusesse a carne da pesquisadora, ou seja, como se as percepções espaciais fossem encarnadas de forma que não pudesse haver separação. Para Collot (2013, p. 85), “O sujeito parece sair de si mesmo para se espraiar por todo o espaço circundante, uma espécie de ubiquidade, que poder ser feliz ou vertiginosa". Não há roteiro estabelecido, e o corpo é levado pelas silhuetas imaginárias construídas no experienciar da/na rua, ou seja, há uma intencionalidade que se faz ao caminhar. Por consequência, o corpo da pesquisadora é incorporado à própria rua e o olhar sobre os outros corpos se instala. Como menciona Marandola Jr.:

\begin{abstract}
Parece que apurar nosso "faro a inteligibilidade aparente das coisas, seu som, seu cheiro, forma, fala [ando] para e através das reações de nosso coração, respondendo a olhares e linguagem, tons e gestos das coisas entre as quais nos movemos" ainda e uma forma possível não apenas da reação estética, defendida por Hillman (1993, p. 21), mas, sobretudo de acesso à cidade. A tarefa criativa e o trabalho intelectual estão ligados a experiência corpórea do caminhar e do perder-se/encontrar-se na/da cidade. (MARANDOLA JR., 2013, p. 161)
\end{abstract}

A experiência demonstrada por Marandola Jr. (2013) é de proximidade errante por um querer fenomenológico; da mesma forma, a posição desta narrativa na rua constróise quando o corpo se deixa levar pela intencionalidade diante de outros corpos, no sentido de que nos fazemos no contato com os outros.

Dessa forma, não estamos no espaço e no tempo, somos o espaço e o tempo (MERLEAU-PONTY, 2006), visto que os nossos corpos se aplicam a eles e os abarcam, ou seja, o espaço da rua pode ser relacionado à significância de espaço merleau-pontyana, em que estamos num espaço no qual existimos. Nas reflexões de Lima (2015), para 
Merleau-Ponty há uma imbricação ontológica entre homem e a realidade objetiva (geográfica) através do corpo, ou seja, o ser-no-mundo enraizado na materialidade espacial. Segundo Lima (2013), outros autores, mesmo em debates não fenomenológicos, citavam indiretamente o sujeito e o corpo em suas concepções de espaço:

A “concepção de espaço como um híbrido", proposta por Santos (1996, p. 204), parece ser, de outro modo, reveladora da ideia de sujeitos corporificados igualmente como híbridos. Considerar o corpo como uma unidade híbrida reunindo, a um só tempo, atributos de sujeito e objeto vai ao encontro de uma geografia viva atenta tanto às escalas de decisão das ações quanto às escalas de impacto das ações, subjacente tanto ao campo das verticalidades quanto ao das horizontalidades, afeita tanto ao território em si mesmo quanto ao seu uso, franqueada tanto aos objetos do pensamento geográfico quanto aos sujeitos do fazer geográfico.(LIMA, 2013, p. 8)

Há, portanto, uma imbricação do nosso corpo com o espaço e, dessa maneira, existe uma trama entre os fenômenos, no sentido de que o corpo se relaciona com o espaço e dele não pode estar separado; essa relação ocorre através do outro num espelhamento que compõe a espacialidade dos corpos, o que também é mencionado por Massey (2008). Nesta narrativa, há a sensação de imbricação entre os "elementos" espaciais.

\subsubsection{Narrativa 2 - quando o corpo altera a posição}

Diferentemente da narrativa em que o corpo se incorpora à rua, esta narrativa destaca-se quando o corpo da pesquisadora sai a campo experimental no sentido de conhecer/conversar com outros corpos. A narrativa de número dois é proveniente de trabalhos de campo, nos quais foram realizadas três entrevistas com indivíduos que vivenciam a Rua Fernandes Pinheiro, ou seja, os sujeitos que experienciam esta rua por meio de seu corpo e de um local fixo na maior parte do tempo. São lojistas ou trabalhadores de "locais fixos" de estabelecimentos que foram escolhidos de acordo com a maior temporalidade em que estão alocados na Rua Fernandes Pinheiro; dessa forma, há estabelecimentos com dez a quarenta anos de existência. Nessas entrevistas 
qualitativas, por meio de questionário prévio semiestruturado, pudemos apreender, através de caminhos perceptivos, que, em sua maioria, os corpos-sujeitos entrevistados compõem relações com a rua, bem como relações de trocas com outros corpos (quando há troca de dinheiro entre os ambulantes e lojistas).

Nossos corpos contribuem para a organização espacial do espaço público e das relações sociais, visto que são cognoscentes, ligados ao espaço, são fatos sociais, psicológicos, culturais e religiosos, uma vez que a nossa existência corporal está imbuída de um contexto relacional. Somos imersos em uma cultura em que nossos corpos são sítios de prazer e de dor, são públicos e privados, têm fronteiras permeáveis, são materiais, discursivos e físicos, são dominados e dominadores de outros corpos. Há, portanto, relações entre os indivíduos que se expressam por meio desse corpo-sujeito que vai ao encontro do mundo, que pode expandir-se ou retrair-se diante do que encontra.

A partir dessa potencialidade relacional de nossos corpos, há aqueles ${ }^{13}$ que já se sentem incorporados à rua, o que se pode ilustrar a partir da frase "eu sou essa rua aqui", pois seu próprio reconhecimento como indivíduo humano se deu atrelado à rua. Outros veem a rua como local de existência de multiplicidades, em que cada indivíduo está em busca de sobrevivência. Ou, ainda, como local de traumas corporificados - "é uma dor que tá no estômago" - quando o corpo foi vítima de assalto e a dor manifestou-se corporalmente por meio da memória. É válido lembrar que os indivíduos e suas falas não são tomados como verdades positivas, porém ressaltam-se as expressões em que a rua é incorporada ao corpo enquanto fenômeno.

Dessa maneira, os locais escolhidos configuram pontos fixos onde as experiências ancoradas pela rua se dão em circuito fechado (no sentido material do trabalho), em que os indivíduos experienciam vivências distintas, mas ao mesmo tempo hibridizadas. Nessa visão, se toda experiência espacial é corporificada, o meu corpo experimenta o espaço de tal forma que, ao mesmo tempo, sou igualmente feito por outros corpos. Semelhantemente, Lima (2007) argumenta que o espaço percebido se funde à paisagem

\footnotetext{
13 Nesta narrativa, optamos por não trazer as expressões das falas dos sujeitos em sua integralidade, bem como seus nomes.
} 
pelo conjunto de corpos e variedade de perspectivas. Nesta narrativa, a posição do corpo perante outros corpos é de um observador encarnado, dotado de percepção sensível diante do outro. Aqui temos o corpo-sujeito (MERLEAU-PONTY, 2006), este que habita o mundo de dentro, situado em um espaço e tempo específicos, e o espaço percebido através da percepção.

\subsubsection{Narrativa 3 - quando o corpo é atravessado pelo pensamento-paisagem}

O interessante é que meus pensamentos precipitaram-se comigo quando deveriam ter ficado nas nuvens, que era onde eu tinha a cabeça. Mas que imprevisível e irrefreável pode ser o pensar. E que rápido, a ponto de avançar sobre as coisas por sua conta e risco deixando-nos para trás feito uma carga que estorvasse a sua mobilidade. (RAMIL, 2008, p. 169)

Considerando que a paisagem e o espaço percebido demandam de um sujeito a sua experiência corporal de percepção (LIMA, 2007), para esta investigação, o pensamento-paisagem (COLLOT, 2013) que atravessou essa experiência foi recorrente de cotidianos experimentados em outra vila, bairro ou cidade. Vejamos quando o corpo da pesquisadora experimentou outra vila na cidade de Ponta Grossa-PR (afastamento do corpo em relação à rua): ao andar pela Vila Estrela, pude viver um sentimento de redimensionamento de mim mesma. Deixei meus olhos percorrerem novas calçadas, novos rostos, ruas e lojas. A sensação é de outra cidade, em que vários status sociais existem acima do meu, isto é, independentemente da consciência em torno do fundamento material das diferenças de classes sociais, o conteúdo social de uma vila produz uma discursividade que mobiliza o poder de afetar o nosso corpo e produzir hierarquias posicionadas a partir do corpo - acima, abaixo. Isso me fez perceber como é possível, dentro de uma mesma cidade (que não é uma metrópole), vivenciar outra cidade. Fui transportada pelo meu corpo para outra cidade como em uma viagem na qual meus olhos viram o novo. 
Em outro relato, a Rua Fernandes Pinheiro foi atravessada pelo imaginário da memória residual da cidade de Pelotas, no Rio Grande do Sul'4, no século XIX e início do século XX, marcados por um ecletismo arquitetônico, entre eles o estilo Neoclássico. 0 encantamento corporal é pelo calçamento antigo e pela arquitetura das casas estreitas e do horizonte visível, como se no fim houvesse um porto com um cais e navios. Nesse momento, o pensamento-paisagem vagueia pelos séculos XIX e XX. Como se nas escadas em frente à Estação São Paulo - Rio Grande (conhecida como Estação Saudade) pudéssemos mirar o oceano e estivéssemos no alto de um cais. A atmosfera experimentada naquele local é remontada também pelo vento no rosto e pela sensação corpórea de distanciamento do ano em questão, 2018, e pela experimentação do presente atrelado ao século XIX e início do século XX. O imaginário mistura-se à literatura de Vitor Ramil em Satolep (2008), em que parecemos buscar a cidade imaginária ou, ainda, o "verdadeiro fado"15" procurado por Marandola Jr. (2016). Para este último, mesmo a busca verdadeira com o olhar perante o fenômeno não pode definir-se como a verdade sobre ele.

A composição da paisagem da Rua Fernandes Pinheiro, a partir desta narrativa, acontece enquanto uma assemblage vivida, uma figuração espacial, como indica Massey (2007), com temporalidades relacionadas e contingentes, onde o espacial, por meio do desenrolar de interações “torna-se o gerador de narrativa” (MASSEY, 2007, p. 146). Com isso, a rua, enquanto ambiente percebido, está imbricada com a intencionalidade do corpo em articulação com imaginários sobre ela, sobre com o que se assemelha, com o que ela pode se comparar e com as sensações que causa. Com isso, também se incluem a intencionalidade, o temperamento cerebral e o momento, articulando o corpo, a projeção do olhar, somados às interações e inter-relações com os significantes, como a arquitetura, os animais, a vegetação, as pessoas, e pela própria existência naquele espaço,

\footnotetext{
${ }^{14}$ A relação com a cidade de Pelotas-RS é resultado da experiência urbana entre os anos de 2012 e 2013 , em que houve uma relação de geograficidade (DARDEL, 2011) com a cidade de nascença, o que possibilitou o enraizamento do ser-no-mundo.

15 O "verdadeiro fado" refere-se ao estilo musical português buscado por Marandola Jr. (2016) em sua primeira viagem a Portugal; a ironia com a ideia de "verdadeiro" é um recurso linguístico para se contrapor aos sentidos das apresentações musicais preparadas para os turistas.
} 
desencadeando uma paisagem enquanto ambiente percebido, uma paisagem assemblage (BENETT, 2005).

Para Lima (2007), é necessário reconhecer que a paisagem contempla um sujeito encarnado e que a complexidade em que se insere é passível de inúmeras interpretações. Os sujeitos percebidos nesta narrativa são composições do real e do imaginário, do passado e do presente.

\section{Considerações finais}

Tendo em vista as menções de Marandola Jr. (2016) sobre a constituição do fazer fenomenológico perante o caminhar científico, bem como as abordagens de Feyerabend (1977) sobre novas formas de pensar e fazer ciência, as abordagens aqui apresentadas constituem aproximações teóricas e práticas de pensar o corpo atrelado às percepções da rua como forma de apreensão do cotidiano urbano. Nesse caso, o significado de "urbano e cotidiano" foi algo que se constituiu no texto a partir da experiência do corpo na rua, na apreensão dos fenômenos e não dos conceitos apriorísticos.

Procuramos elucubrar as potencialidades do corpo como lócus metodológico através de três exercícios experimentais que se diferenciam pela posição do corpo perante o espaço. Temos o corpo ligado à situacionalidade e à forma de ser-no-mundo (narrativa um), o corpo observador da pesquisadora em articulação com os significantes (narrativa dois), e o horizonte paisagístico produzindo um pensamento-paisagem que interfere na experimentação/sensação do corpo no espaço (narrativa três). Não obstante, os textos narrativos foram escritos por três corpos em diálogo com o horizonte das experiências da rua e de diferentes leituras bibliográficas.

Nas considerações de Marandola Jr. (2013), é a geografia com “g” minúsculo que fornece a geografia constituinte do mundo. Destarte, é a apreensão do cotidiano urbano atrelado à rua a partir do corpo que nos interessa, do mesmo modo que a valorização do corpo-sujeito (MERLEAU-PONTY, 2006) como recurso metodológico para apreensão do espaço e da paisagem. Portanto, os exercícios experimentados compõem formas de apreender a cidade a partir de um fazer fenomenológico que contempla uma assemblage 
vivida (arranjos socioespaciais provisórios), isto é, paisagens horizontes (formas de pensamento), as quais, conforme defende Benett (2005), acontecem pela vivência, pelo movimento e pela interação com os significantes (pesquisadores e corpos na rua). Em síntese, uma contribuição metodológica na discussão de fenômenos encarnados cuja força existencial é figurada pelo "ethos efêmero" que também compõe o cotidiano geográfico de ruas populares na urbe contemporânea.

\section{Referências}

ALMEIDA, Maria Geralda. A propósito do trato do invisível, do intangível e do discurso na geografia cultural. Revista da ANPEGE, João Pessoa, 9, n. 11, p. 41-50, 2013. Disponível em: https://ojs.ufgd.edu.br/index.php/anpege/article/viewFile/6490/3471. Acesso em: 29 out. 2018.

BARBOSA, Maria Raquel; MATOS, Paula Mena; COSTA, Maria Emília. Um olhar sobre o corpo: o corpo ontem e hoje. Psicologia \& Sociedade, Belo Horizonte, v. 23, n. 1, p. 24-34. 2011. Disponível em:

http://www.scielo.br/scielo.php?pid=S010271822011000100004\&script=sciabstract\&tlng=p t. Acesso em: 02 jul. 2018.

BENETT, Jane. The agency of assemblages and the North American blackoute. Public Culture, Durhan: Duke University, v. 17, n. 3, p 445-465, 2005. Disponível em: https://jscholarship.library.jhu.edu/bitstream/handle/1774.2/32808/bennet_public_culture. pdf. Acesso em: 05 ago. 2019.

BESSE, Jean-Marc. Ver a Terra: seis ensaios sobre a paisagem e a geografia. São Paulo: Perspectiva, 2006. 108 p.

BETTANINI, Tonino. Espaço e ciências humanas. Rio de Janeiro: Paz e Terra, 1982. 157 p.

COLLOT, Michel. Poética e filosofia da paisagem. Rio de Janeiro: Oficina Raquel, 2013. 204 p.

COSTA, Benhur Pinós da; GOERGEN, Édipo Djavan dos Reis; DURGANTE, Flavia R. Nascimento; Taiane Flores. O corpo e a geografia do cotidiano. In: AZEVEDO, Ana Francisca de; REGO, Nelson. (orgs.). Geografia e (in) visibilidades: paisagens, corpos, memórias. Porto Alegre: Compasso Lugar-Cultura, 2017. p. 349-381. 
CHAUÍ, Marilena. Merleau-Ponty: da constituição à instituição. Cadernos Espinosanos /

Estudos Sobre o século XVII, São Paulo: Departamento de Filosofia da FFLCH-USP, n. 20, p. 11-37, jun. 2009. Disponível em:

https://www.scribd.com/document/118214879/Cadernos-Espinosa-20. Acesso em: 20 de abr. 2018.

DARDEL, Éric. O homem e a Terra: natureza da realidade geográfica. São Paulo: Perspectiva, 2011. $173 \mathrm{p}$.

DAVIM, David Emanuel Madeira; MARANDOLA JR, Eduardo José. O pensamento fenomenológico na educação geográfica: caminhos para uma aproximação entre cultura e ciência. Caderno de Geografia, Belo Horizonte: v. 26, n. 47. p. 684-713, 2016. Disponível em: http://periodicos.pucminas.br/index.php/geografia/article/view/p.23182962.2016v26n47p684. Acesso em: 01 ago. 2018.

FEYERABEND, Paul. Contra o método. Rio de Janeiro: F. Alves, 1977. 488 p.

GOMES, Paulo. César da Costa. Geografia e modernidade. Rio de Janeiro: Bertrand Brasil, 1996. 366 p.

HERMANN, Carla Guimarães. Cidade e cotidiano: a contribuição dos situacionistas. In: ENCONTRO DE GEÓGRAFOS DA AMÉRICA LATINA, 10., 2005, São Paulo. Anais [...]. São Paulo: Universidade de São Paulo, 2005. p. 6868-6886. Disponível em:

http://observatoriogeograficoamericalatina.org.mx/egal10/Teoriaymetodo/Conceptuales/ 20.pdf. Acesso em: 05 jun. 2018.

JACQUES, Paola Berenstein (org.). Apologia da deriva: escritos situacionistas sobre a cidade. Rio de Janeiro: Casa da Palavra, 2003.160 p.

JACQUES, Paola Berenstein (org.). Elogio aos errantes. Salvador: EDUFBA, 2012. 331 p.

LIMA, Elias Lopes de. Do corpo ao espaço: contribuições da obra de Maurice MerleauPonty à análise geográfica. Revista GEOgraphia, Niterói: PPGEO/UFF, ano IX, n. 18, p. 6584, 2007. Disponível em: https://periodicos.uff.br/geographia/article/view/13543. Acesso em: 08 out. 2018.

LIMA, Elias Lopes de. O lugar do sujeito em a natureza do espaço de Milton Santos.

Revista Geografia, Recife: v.3, n. 2, p. 1-8, 2013. Disponível em: http://www2.fct.unesp.br/docentes/geo/necio turra/PPGG\%20\%20PESQUISA\%20QUALI\%20PARA\%20GEOGRAFIA/Lima_0\%20lugar\%20do\%20sujeito\%20em \%20Milton\%20Santos.pdf. Acesso em: 28. out. 2018. 
LIMA, Elias Lopes de. Os limites da geografia humanista e da nova geografia cultural na compreensão do sujeito. Ensaios de Geografia, Rio de Janeiro: v. 2, n. 4, p. 7-31, $2014 a$. Disponível em: www.ensaios-posgeo.uff.br/index.php/EG/article/view/46/56. Acesso em: 08 out. 2018.

LIMA, Elias Lopes de. O sujeito entre as múltiplas geografias e a geografia geral. In: ENCRUZILHADAS GEOGRÁFICAS: notas sobre a compreensão do sujeito na teoria social crítica. Rio de Janeiro: Consequência, 2014b. p. 167-176.

LIMA, Elias Lopes de. A corporeidade como um recurso metodológico da geograficidade. Revista de Geografia, Recife, v. 5, p. 1-11, 2015. Disponível em: https://geografia.ufjf.emnuvens.com.br/geografia/article/download/93/93. Acesso em: 06 set. 2018.

LINDÓN, Alicia. La construcción socio-espacial de la ciudad. Desde la perspectiva del sujeto-cuerpo y el sujeto sentimento. In: CONGRESO DE LA ASOCIACIÓN LATINOAMERICANA DE SOCIOLOGÍA, 27., 2009, Buenos Aires. Asociación Latinoamericana de Sociología. Anais [...]. Buenos Aires, 2009. p. 1-11. Disponível em: https://dialnet.unirioja.es/descarga/articulo/3320514.pdf. Acesso em: 06 abr. 2018.

MARANDOLA JR., Eduardo. Trilhas de acesso a Lisboa: poesia, música, imagem e som em O céu de Lisboa (Lisbon Story), de Wim Wenders. In: CAZETTA, Valéria; OLIVEIRA JR., Wenceslao Machado de (orgs.). Grafias do espaço: imagens da educação geográfica contemporânea. Campinas: Alínea, 2013. p. 143-165.

MARANDOLA JR., Eduardo. Geografias do porvir: a fenomenologia com abertura para o fazer geográfico. In: SPOSITO, Eliseu Sauvério; SILVA, Charlei Aparecido da; SANT'ANNA NETO, Joao Lima; MELAZZO, Everaldo Santos. (orgs.). A diversidade da geografia brasileira: escalas e dimensões da análise e da ação. Rio de Janeiro: Consequência, 2016. p. 451-466.

MASSEY, Doreen. Pelo espaço. uma nova política da espacialidade. Rio de Janeiro: Bertrand Brasil, 2008. 312 p.

MCFARLANE, Colin. Translocal assemblages: space, power and social movements. Geoforum., Durham, n. 40, p. 561-567, May 2009. Disponível em: http://blogs.ubc.ca/politicalgeography/files/2015/09/mcfarlane translocal_assemblages.p df. Acesso em: 15 fev. 2020.

MERLEAU-PONTY, Maurice. Fenomenologia da percepção. São Paulo: Martins Fontes, 2006. $662 \mathrm{p}$. 
NOGUÉ, Joan; ROMERO, Joan. Otras geografias, otros tiempos, nuevas y viejas preguntas, viejas y nuevas respuestas. In: NOGUÉ, Joan; ROMERO, Joan. (dir.). Las otras geografias. Valencia: Tirant La Blanch, 2006. p. 15-49.

RAMIL, Vitor. Satolep. São Paulo: Cosac Naify, 2008. 288 p.

SKEWES, Juan Carlos. Patrimonio, paisaje y convivencialidad: experiencias de desposesión en el sur de Chile. GeoGraphos, Alicante, v. 7, n. 87, p. 1-17, jan. 2016. Disponível em: https://www.researchgate.net/publication/311658070_Patrimonio_paisaje_y_convivencial idad_experiencias_de_desposesion_en_el_sur_de_Chile. Acesso em: 08 dez. 2020.

SENNETT, Richard. Carne e pedra: o corpo e a cidade na civilização ocidental. Rio de Janeiro: Record, 1997. 362 p.

TUAN, Yi-Fu. Espaço e lugar: a perspectiva da experiência. Londrina: Eduel, 2013. 248 p.

Recebido em: 16/05/2020

Aprovado em: 07/02/2021

Universidade do Estado de Santa Catarina - UDESC

Centro de Ciências Humanas e da Educação - FAED

PerCursos

Volume 22 - Número 48 - Ano 2021 revistapercursos@gmail.com 